\title{
The Ocean's Role in Continental Climate Variability and Change
}

\author{
DIETMAR DOMMENGET \\ Leibniz Institute for Marine Sciences, Kiel, Germany \\ (Manuscript received 7 August 2008, in final form 23 February 2009)
}

\begin{abstract}
A characteristic feature of global warming is the land-sea contrast, with stronger warming over land than over oceans. Recent studies find that this land-sea contrast also exists in equilibrium global change scenarios, and it is caused by differences in the availability of surface moisture over land and oceans. In this study it is illustrated that this land-sea contrast exists also on interannual time scales and that the ocean-land interaction is strongly asymmetric. The land surface temperature is more sensitive to the oceans than the oceans are to the land surface temperature, which is related to the processes causing the land-sea contrast in global warming scenarios. It suggests that the ocean's natural variability and change is leading to variability and change with enhanced magnitudes over the continents, causing much of the longer-time-scale (decadal) global-scale continental climate variability. Model simulations illustrate that continental warming due to anthropogenic forcing (e.g., the warming at the end of the last century or future climate change scenarios) is mostly $(80 \%-90 \%)$ indirectly forced by the contemporaneous ocean warming, not directly by local radiative forcing.
\end{abstract}

\section{Introduction}

A well-known feature of global warming scenarios is the land-sea contrast, with stronger warming over land than over oceans. Several recent studies find that this land-sea contrast is not just a transient effect due to the larger heat capacity of the oceans relative to the heat capacity of the land (Sutton et al. 2007; Lambert and Chiang 2007; Joshi et al. 2007). It is an inherent feature of global warming that exists in the equilibrium climate state of global warming scenarios. Sutton et al. (2007) explain the land-sea contrast by differences in the local latent heat releases over land and oceans, which lead to different negative feedbacks. However, they do not consider any ocean-land interaction. Joshi et al. (2007) explain the land-sea contrast in more detail, including the importance of global mixing of the free atmosphere. They find that the different moisture availability over land and ocean leads to different atmospheric temperature lapse rates (latent heat release), which in combination with a well-mixed free (above boundary layer) atmosphere can explain the land-sea contrast. Thus they

Corresponding author address: Dietmar Dommenget, Leibniz Institute for Marine Sciences, Düsternbrooker Weg 20, D-24105 Kiel, Germany.

E-mail: ddommenget@ifm-geomar.de implicitly argue that ocean-land interaction is an important factor. Compo and Sardeshmukh (2009) argue, based on model simulation with prescribed historical SSTs, that most of the continental warming is caused by the ocean warming and not by the local response the radiative forcings.

The studies discussed above mainly focus on the anthropogenic forcings, but the results have some more general implications for the role of the ocean's natural variability and change for continental variability and change. There is in principle no reason why the processes described by Joshi et al. (2007) shall not be present on interannual or longer time scales of natural climate variability, which is also supported by model simulations for the estimation of climate sensitivity (Cess et al. 1990).

Cess et al. (1990) note, although in the context of climate sensitivity, that the continents respond to global mean changes in ocean temperatures with amplified amplitudes. Subsequently it may seem possible that the land-sea contrast exists in natural climate variability as well. This is also indicated by Lambert and Chiang (2007), studying the interannual residual $r$ from the land-sea warming. These results could suggest that the oceans are not lagging behind the fast warming of the continents but may indeed be the driving force of natural variability and anthropogenic climate change over continents. 
In this study the land-sea contrast is reinvestigated in observations and general circulation model (GCM) experiments to illustrate the role of asymmetric oceanland interaction in natural and externally forced climate variability. It will be shown that the continental surface temperatures $T_{\text {land }}$ are much more sensitive to changes in the ocean temperatures $T_{\text {ocean }}$ than $T_{\text {ocean }}$ is sensitive to changes in $T_{\text {land }}$. The results are summarized and discussed in the context of a simple conceptual box model.

In the following section the data and model simulations are introduced. In the first analysis section (section 3 ) the mean ocean and land temperature variability in observations and different GCM simulations are discussed. In the second part of the analysis, in section 4, a series of GCM sensitivity experiments are discussed; those results are then summarized and discussed with the help of simple box model in section 5. In the subsequent section 6 some asymmetries in the land and ocean water vapor content and atmospheric heating are illustrated to highlight some possible feedbacks that maintain the asymmetry in the land-sea interaction. In the final section the results of this study are summarized and discussed.

\section{Data and models}

Observations of land surface temperatures are taken from the Climatic Research Unit Temperature dataset, version 3 (CRUTEM3v) covering gridded, but incomplete, global land data from 1850 to 2007 (Brohan et al. 2006). The number of observations that go into the CRUTEM3v dataset is improving with time (see Fig. 1a). After 1950 the area coverage was mostly above 30\%, while it is roughly linearly decreasing back in time to near zero in 1850 . In addition to sampling errors there may also be other errors or characteristics in the data that may lead to problems in comparing these data with model simulations (e.g. Pielke et al. 2007). Observed sea surface temperatures for 1870-2003 are taken from the Hadley Centre Sea Ice and Sea Surface Temperature dataset (HadISST) (Rayner et al. 2003). Similar to the land data the area coverage is decreasing back in time, with above $50 \%$ area coverage after 1950 (see Fig. 1a).

The reduced data coverage in both datasets before 1950 may cause serious problems in statistical analysis of the covariance between the two datasets, as is illustrated with the correlation and regression between the linear detrended land and ocean mean in Fig. 1b. Both statistical variables strongly degrade if they are estimated over time spans before 1950 . The subsequent analysis present in this work will therefore only discuss com-
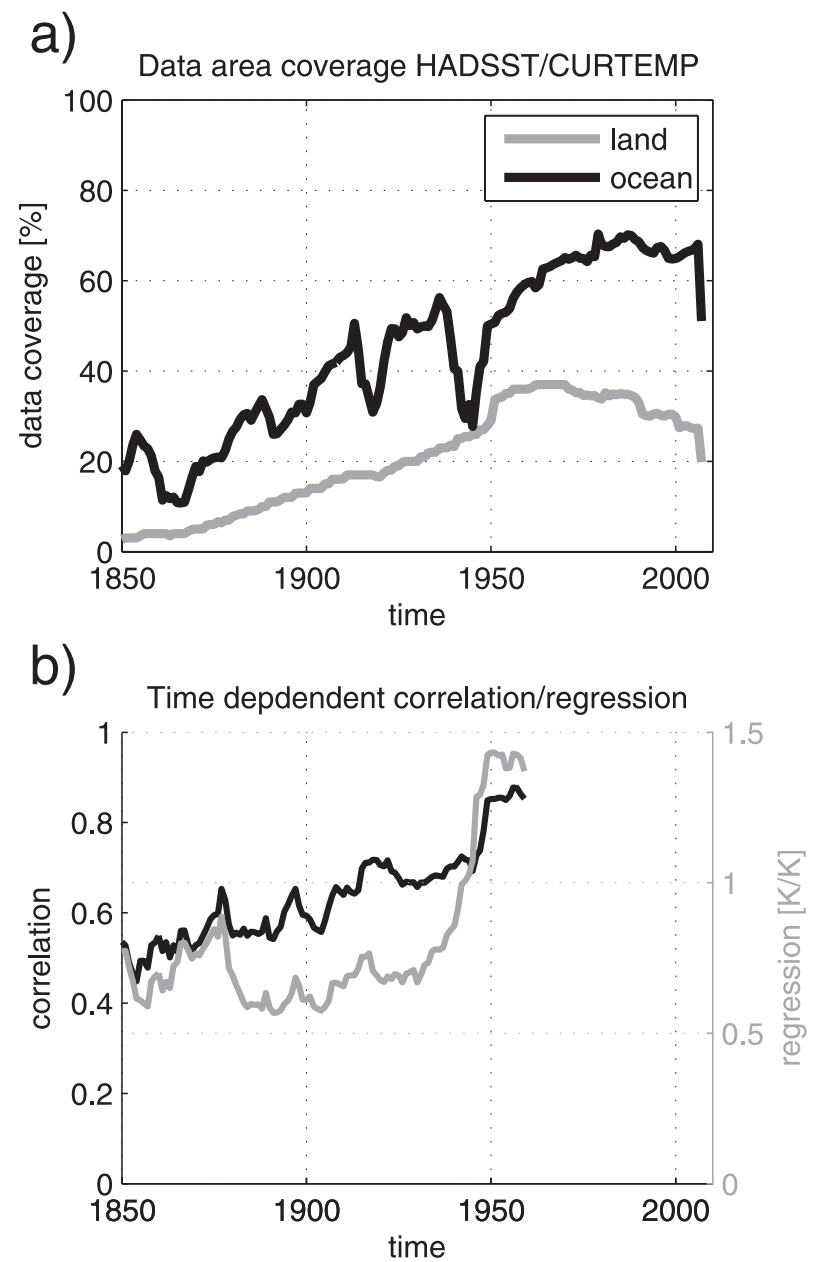

FIG. 1. (a) The total spatial data coverage of observed land and ocean surface temperature. (b) The correlation and regression parameter between linear detrended land and ice-free ocean mean surface temperature estimated over a 50-yr time interval as function of the first date of the estimation time interval used.

parisons of observed land and ocean data after 1950. Note, however, that simulations using the ocean data prior 1950 as forcing are still discussed, although they are not compared against the observed land data.

All simulations are based on the atmospheric GCM ECHAM5 (Roeckner et al. 2003) with a horizontal resolution of $\mathrm{T} 31\left(3.75^{\circ} \times 3.75^{\circ}\right)$ and 19 vertical levels (see Table 1 for a complete list of simulations used) except for the ECHAM-HadISST, which are performed at T106 $\left(1.125^{\circ} \times 1.125^{\circ}\right)$ and 31 vertical levels (Latif et al. 2007). The ECHAM-HadISST consists of 5 ensemble members all forced with the observed SST from HadISST and all other boundary forcings fixed to climatological values.

The coupled ocean-atmosphere integrations (TLAND + $1 \mathrm{~K}, \mathrm{OZ}, \mathrm{OZ}-2 \times \mathrm{CO}_{2}$ and FIXLAND-2 $\times \mathrm{CO}_{2}$ ) use the 
TABLE 1 . The model simulations discussed in this study.

\begin{tabular}{|c|c|c|c|c|}
\hline Experiment name & Length (years) & $\begin{array}{l}\text { Atmosphere } \\
\text { model }\end{array}$ & $\begin{array}{l}\text { Ocean } \\
\text { model }\end{array}$ & Comments \\
\hline $\mathrm{SST}+1 \mathrm{~K}$ & $2 \times 20$ & $\begin{array}{l}\text { ECHAM5 } \\
\text { T31 resolution }\end{array}$ & None & $\begin{array}{l}\text { Global SST } \pm 1 \mathrm{~K} \text { uniformly. Sea ice cover and } \\
\text { thickness is climatologically prescribed. }\end{array}$ \\
\hline TLAND + 1K & $2 \times 20$ & $\begin{array}{l}\text { ECHAM5 } \\
\text { T31 resolution }\end{array}$ & $\mathrm{OZ}$ & $\begin{array}{l}\text { Global land } T_{\text {surf }} \pm 1 \mathrm{~K} \text { uniformly and coupled } \\
\text { with the OZ ocean model. }\end{array}$ \\
\hline ECHAM5-HadISST & $5 \times 134$ & $\begin{array}{l}\text { ECHAM5 } \\
\text { T106 resolution }\end{array}$ & None & Historical SST and sea ice from 1870 to 2003. \\
\hline $\mathrm{OZ}$ & 2000 & $\begin{array}{l}\text { ECHAM5 } \\
\text { T31 resolution }\end{array}$ & $\mathrm{OZ}$ & Coupled with simple (no dynamics) ocean OZ. \\
\hline ECHAM-HadISST-T31 & 134 & $\begin{array}{l}\text { ECHAM5 } \\
\text { T31 resolution }\end{array}$ & None & $\begin{array}{l}\text { As ECHAM-HadISST, but with the lower-resolution } \\
\text { atmosphere model from OZ. }\end{array}$ \\
\hline ECHAM-OZSST & 200 & $\begin{array}{l}\text { ECHAM5 } \\
\text { T31 resolution }\end{array}$ & None & SST and sea ice from $200 \mathrm{yr}$ of OZ. \\
\hline $\mathrm{OZ}-2 \times \mathrm{CO}_{2}$ & 100 & $\begin{array}{l}\text { ECHAM5 } \\
\text { T31 resolution }\end{array}$ & $\mathrm{OZ}$ & As $\mathrm{OZ}$, but $2 \times \mathrm{CO}_{2}$ concentrations $(700 \mathrm{ppm})$. \\
\hline FIXSST $-2 \times \mathrm{CO}_{2}$ & 100115 (control) & $\begin{array}{l}\text { ECHAM5 } \\
\text { T31 resolution }\end{array}$ & None & $\begin{array}{l}2 \times \mathrm{CO}_{2} ; \mathrm{SST} \text {, sea ice cover, and thickness are } \\
\text { climatologically prescribed. }\end{array}$ \\
\hline FIXLAND-2 $\times \mathrm{CO}_{2}$ & 5050 (control) & $\begin{array}{l}\text { ECHAM5 } \\
\text { T31 resolution }\end{array}$ & $\mathrm{OZ}$ & $\begin{array}{l}2 \times \mathrm{CO}_{2} ; T_{\text {surf }} \text { over land is climatologically } \\
\text { prescribed and coupled with OZ. }\end{array}$ \\
\hline FIXSURF $-2 \times \mathrm{CO}_{2}$ & 5050 (control) & $\begin{array}{l}\text { ECHAM5 } \\
\text { T31 resolution }\end{array}$ & None & $2 \times \mathrm{CO}_{2} ;$ global $T_{\text {surf }}$ is climatologically prescribed. \\
\hline
\end{tabular}

simple one-dimensional ocean mixed layer model OZ (Dommenget and Latif 2008). The ocean model OZ has 19 vertical layers that are connected through vertical diffusion only. Thus ocean grid points do not communicate with lateral neighbors. The coupled model OZ produces realistic monthly SST variability (Dommenget and Latif 2008), but, because of missing ocean dynamics, SST variability in the tropics is weaker than observed. In comparison to fully coupled GCMs the advantage of this model is that the mean state is much closer to the observed and the structure and amplitude of higher latitudes SST variability is somewhat closer to the observed (at least if compared to some fully coupled GCMs).

The FIXSURF-2 $\times \mathrm{CO}_{2}$ simulation is used to estimate the anthropogenic radiative forcing over oceans and land without feedbacks.

\section{Ocean and land mean temperature variability}

In Sutton et al. (2007), Lambert and Chiang (2007), and Joshi et al. (2007) the linear trend in surface temperatures shows larger amplitudes over land than over ocean. These increased amplitudes over land are not only present in the trends, but also in the linear detrended interannual and decadal climate fluctuations, as shown in Fig. 2a. The ratio of amplitudes is about 1.5 and the correlation is 0.8 , indicating that a significant part of interannual land temperature variability is coherent with ocean temperature variability. As discussed in the previous section, this relationship degrades back in time prior to the 1950s (Fig. 1b), which may be due to the poorer data coverage in the datasets used.

In the observational record it is unclear what drives $T_{\text {ocean }}$ and $T_{\text {land. }}$. It may therefore be argued that both are driven by the same external or internal forcing, but the amplitudes in $T_{\text {ocean }}$ are smaller than those of $T_{\text {land }}$ because of the larger heat capacity of the oceans. This, however, is not the case in the ECHAM-HadISST simulations where $T_{\text {ocean }}$ is prescribed and the only forcing for $T_{\text {land }}$ is the prescribed variability in $T_{\text {ocean }}$. Figure $2 \mathrm{~b}$ shows that the result is supported by the ECHAM-HadISST ensemble mean in which the landsea warming ratio of 1.51 holds over the entire period and the correlation between land and ocean surface temperature is even larger. The individual ensemble members have still a correlation ranging between 0.76 and 0.79 and a land-sea warming ratio ranging between 1.38 and 1.58. It clearly indicates that much of the global mean land temperature variability is forced from the SST.

The analysis can also be applied to the 2000-yr-long coupled ocean-atmosphere control integration $\mathrm{OZ}$ to estimate the ratio for natural SST variability (Fig. 2c). On interannual time scales the land-sea warming ratio is 1.29 and the correlation 0.5 , but for the decadal-scale SST variability the land-sea warming ratio is 1.48 and the correlation 0.8 , indicating that variability in $T_{\text {ocean }}$ causes variability over land with larger amplitudes. The results indicate that much of the land temperature variability is forced from the ocean SST but also illustrate that the OZ simulation deviates somewhat from the observations. 


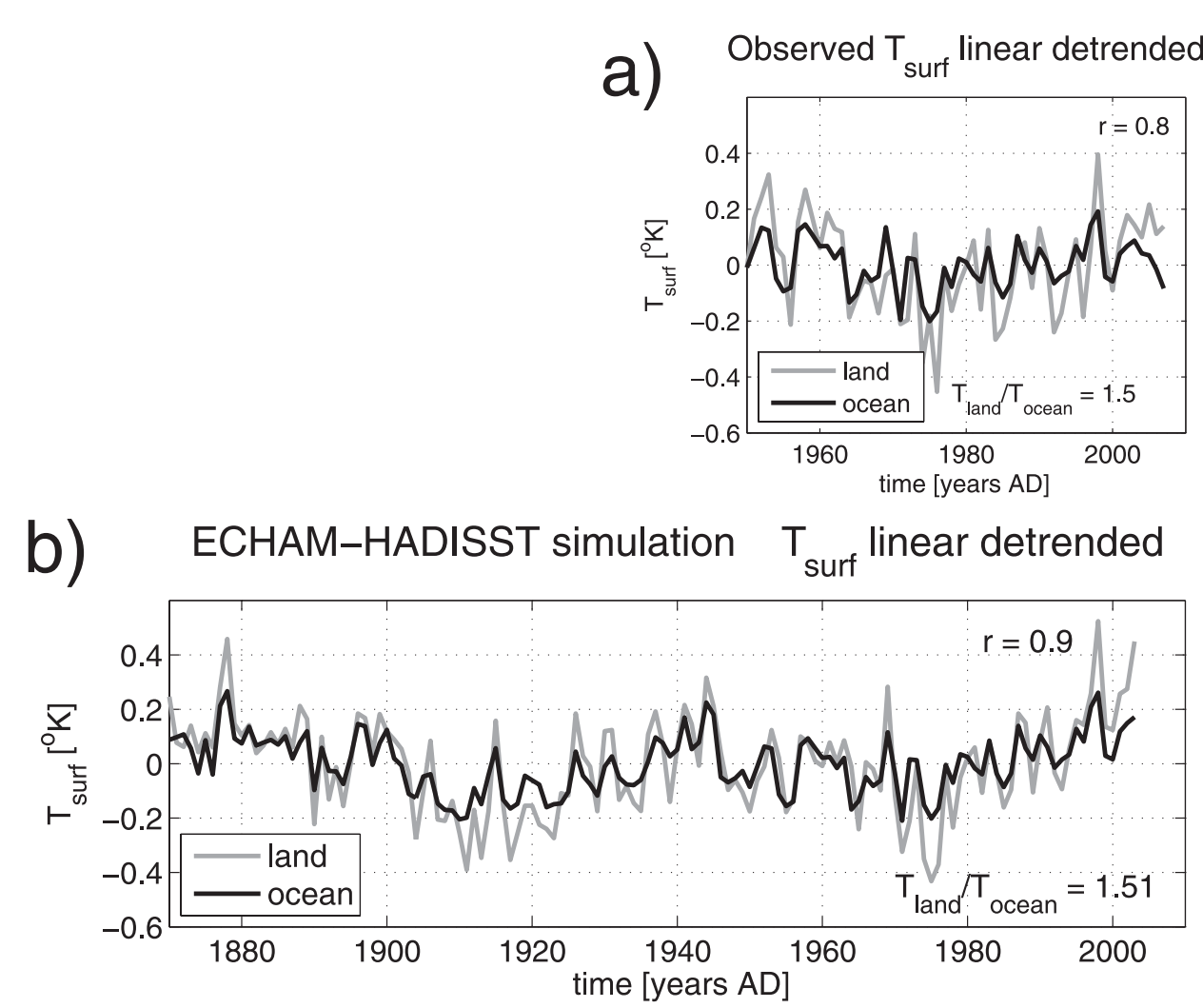

C) Coupled simulation $\mathrm{OZ} \quad \mathrm{T}_{\text {surf }}$ 10yrs mean linear detrended

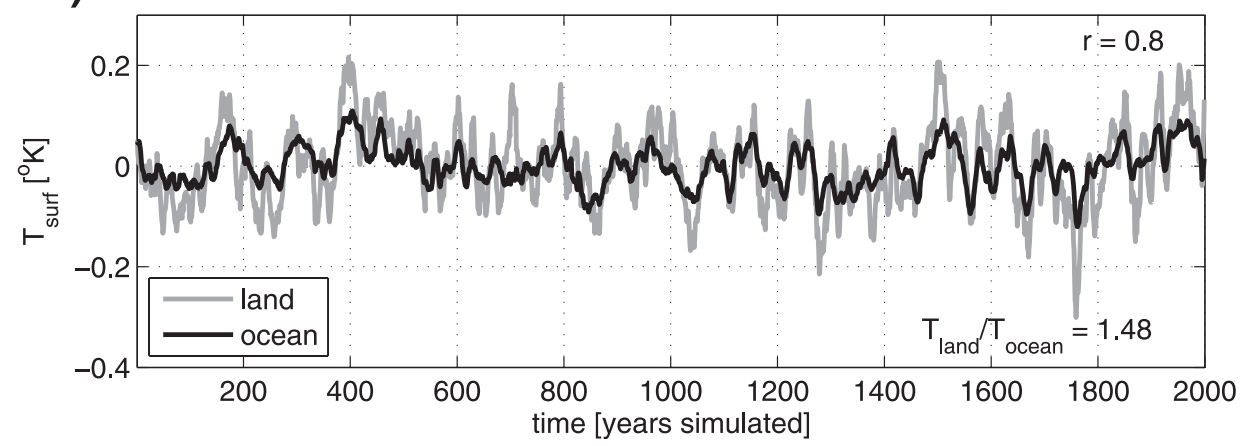

FIG. 2. Time series of linearly detrended annual mean $T_{\text {land }}$ and $T_{\text {ocean }}$ (a) Observed. (b) The simulations with historical SST forcing only (no other forcings; ensemble mean of ECHAM-HadISST). (c) The coupled climate simulation of natural variability $(\mathrm{OZ})$ with linear detrended 10-yr running-mean $T_{\text {surf }}$. The $T_{\text {land }} / T_{\text {ocean }}$ values correspond to the regression coefficient for $T_{\text {land }}$ onto $T_{\text {ocean }} ; r$ marks the correlation value between $T_{\text {land }}$ and $T_{\text {ocean }}$.

The modes of SST variability in coupled model simulations differ in general from those of the observations. The OZ simulation has in particular less variability in the tropics compared to the observed variability because of missing ocean dynamics to support the El Niño mode. Therefore the relative importance of the high-latitude SST variability increases. The difference in the land-sea warming ratio may in some part be a result of these various SST modes, but it could also result from other factors such as differences in the atmospheric models or inherent variations between coupled and atmosphere-only simulations (see, e.g., Barsugli and Battisti 1998; Dommenget 2000; Sutton and Mathieu 2002). To address this issue two additional atmospheric model simulations, which both use the identical atmosphere model (ECHAM5 in T31 horizontal resolution), have been carried out. One simulation is forced with the historical HadISST SST and sea ice (experiment ECHAM-HadISST-T31) and the other 
with the SST and sea ice from $200 \mathrm{yr}$ of the ECHAM5OZ simulation (experiment ECHAM-OZSST). Thus the two simulations differ only in the SST and sea ice boundary conditions. The land-sea warming ratio in the ECHAM-HadISST-T31 $\left(T_{\text {land }} / T_{\text {ocean }}=1.45\right.$ and $\left.r=0.73\right)$ is comparable to that of the higher-resolution model ECHAM-HadISST and the observations, suggesting that the atmospheric model of $\mathrm{OZ}$ can reproduce the land-sea contrast if forced with the right SST variability. However, in the ECHAM-OZSST simulation, the landsea warming ratio $\left(T_{\text {land }} / T_{\text {ocean }}=1.0 ; r=0.3\right)$ is significantly smaller than in the ECHAM-HadISST-T31 simulation and the observations, indicating that the different SST and sea ice variability is causing a weaker land-sea contrast. Furthermore, it has to be noted that the land-sea warming ratio in the ECHAM-OZSST simulation is also smaller than in the $\mathrm{OZ}$ simulation for the same 200 -yr period. The two simulations agree better on decadal time scales and if the analysis is restricted to the tropical belt $\left(30^{\circ} \mathrm{S}-30^{\circ} \mathrm{N} ; \mathrm{OZ}: T_{\text {land }} / T_{\text {ocean }}=1.76\right.$, $r=0.8$ and ECHAM-OZSST: $T_{\text {land }} / T_{\text {ocean }}=1.57 ; r=$ $0.7)$, but the coupled simulation still has a slightly larger land-sea warming ratio. There may be two possible causes for this deviation: First, the uncoupled simulation assumes that the land surface temperatures are caused by the SST variability, which in a coupled system does not need to be the case. If the land surface temperatures vary mostly independent of $T_{\text {ocean }}$ or the SST is partly caused by the land surface temperatures, then the uncoupled model simulation should not be able to reproduce the land-sea warming ratio. These scenarios may be relevant for the higher latitudes, but the relatively good agreement between the ECHAM-OZSST and the OZ simulation in the tropics suggests that at least the tropical land surface temperatures are indeed forced by the SST variability. Second, the deviations could be caused by differences in the model setup. In a coupled model simulation, for instance, the ocean heat capacity is finite, while in an atmospheric model simulation the prescribed SST effectively represents an infinite ocean heat capacity, which does change the heat fluxes to the atmosphere at least in the higher latitudes (see, e.g., Barsugli and Battisti 1998; Dommenget 2000; Sutton and Mathieu 2002). This is a known inherent problem in uncoupled simulations that is not solved yet and does leave some uncertainty in the results of the uncoupled simulations for higher latitudes.

Using a land and ocean mean temperature time series may seem somewhat arbitrary when discussing natural internal variability since modes of natural variability are mostly of regional (not global) scale. Figure 3 illustrates how the land and ocean mean temperature anomaly time series correlate to the local surface temperature variability. Note, first of all, that the correlation maps of $T_{\text {ocean }}$ and $T_{\text {land }}$ are quite similar since they are highly correlated to each other. However, some differences can be seen. With respect to $T_{\text {land }}$ (Figs. 3a,c,e) we can notice that positive correlations are found on all continents but are slightly stronger over the warmer continents (e.g., Africa, South America, and Australia). This finding is similar in the observations and for the ECHAM5HadISST simulation but is different in the ECHAM5$\mathrm{OZ}$ simulation. The latter has largest correlations in northern continents, indicating that $T_{\text {land }}$ variability in this simulation is more dominated by the higher latitudes than by tropical variability, which appears to be consistent with the overall weaker tropical SST variability in the ECHAM5-OZ simulation because of missing ocean dynamics for supporting El Niño dynamics. The $T_{\text {land }}$ index therefore seems to represent a nearglobal feature in the datasets. We can further see that $T_{\text {land }}$ variability in all datasets is related to SST variability in all three tropical oceans with strongest amplitudes in the Atlantic and Indian Ocean. This pattern does not solely project onto any specific known pattern of SST variability (e.g., El Niño) and is very similar to the correlation map of $T_{\text {ocean }}$ variability (Figs. 3b,d,f).

In all three datasets we find that $T_{\text {ocean }}$ variability is mostly correlated with land surface temperature variability in the tropical regions but much less or not at all with higher northern-central continental regions (Figs. 3b,d,f). It is important to note that the coupled ECHAM5-OZ simulation is in these characteristic similar to the ECHAM-HadISST simulation, giving some support for the coupled model. It in particular illustrates that the structure of variability in the ECHAM5-OZ simulation is not that different from the observed, with a restriction for the higher northern latitudes where the model clearly deviates from the observations and the ECHAM5HadISST simulation (cf. Fig. 3e with Figs. 3a,c).

The relevance of $T_{\text {land }}$ variability to local climate variability is quantified by the correlation values, which range from 0 to 0.5 . Therefore, $T_{\text {land }}$ variability will in many regions be of no relevance as such but is of some relevance for many different regions on different continents. Most importantly, $T_{\text {land }}$ variability quantifies climate variability that is not restricted to one particular area on earth or to one particular climate mode, but it is mostly a statistical index that quantifies a specific characteristic of the earth's climate relatively well.

The results of the ECHAM-HadISST-T31 simulation (not shown) are similar to the ECHAM-HadISST simulation with respect to the structures discussed in Fig. 3. The ECHAM-OZSST simulation is also quite similar to the OZ simulation with respect to the structures discussed in Fig. 3 but has a slightly larger (smaller) 
a)

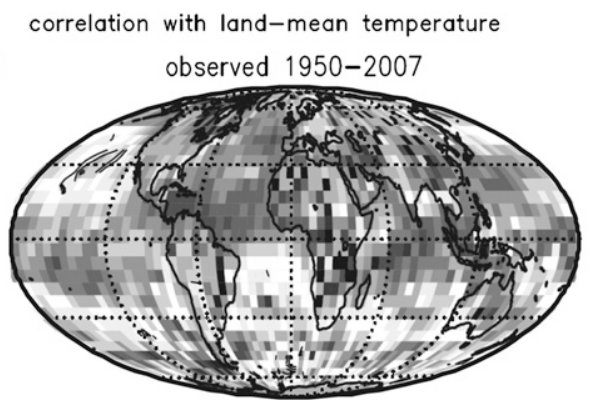

c)

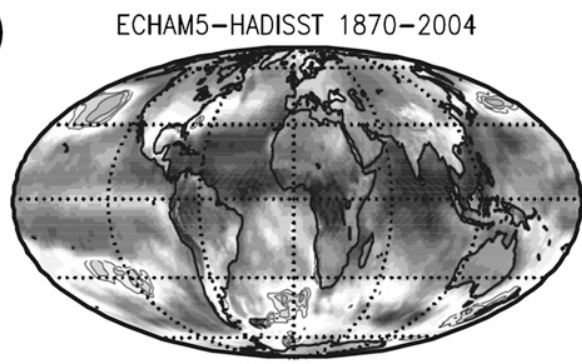

e)

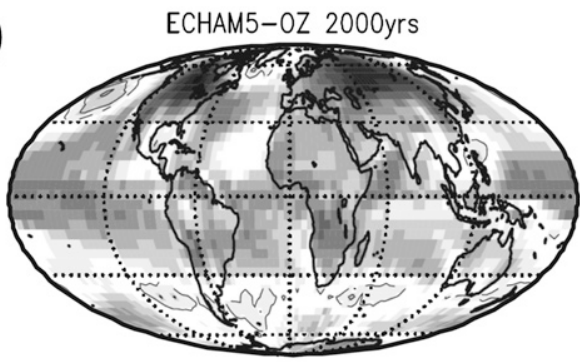

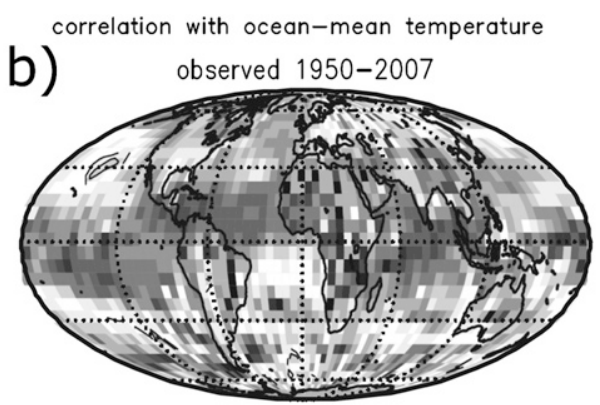

d) ECHAM5-HADISST 1870-2004

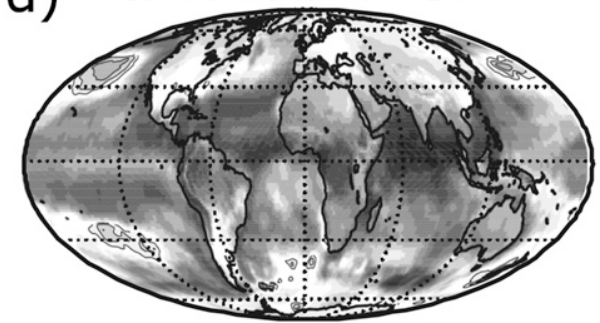

f)

f) ECHAM5-OZ 2000yrs

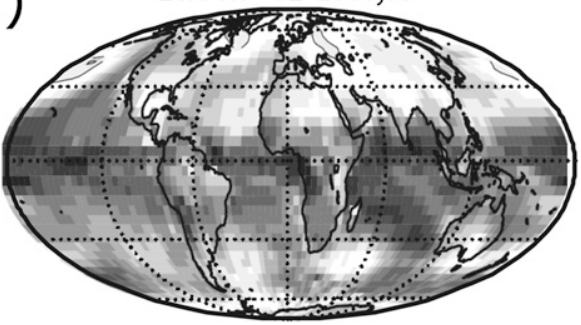

\section{$-0.5-0.45-0.4-0.35-0.3-0.25-0.2-0.15-0.1-0.050 .050 .1 \quad 0.150 .20 .250 .3 \quad 0.350 .40 .450 .5$}

FIG. 3. Correlation between the annual mean linear detrended anomalies of $T_{\text {surf }}$ with (left) $T_{\text {land }}$ and (right) $T_{\text {ocean }}$ (a),(b) Observations; (c),(d) all ensemble members of the ECHAM-HadISST simulation; (e),(f) the coupled OZ simulations. Negative values have contour lines and undefined values in (a),(b) are blank white squares.

correlation of $T_{\text {land }}\left(T_{\text {ocean }}\right)$ variability with the northern continental regions. This is consistent with the lower landsea warming ratio for higher latitudes in the ECHAMOZSST simulation if compared to the OZ simulation as discussed in the previous analysis.

The land-sea warming ratio in the ECHAM-HadISST holds also for the warming trend over the most recent decades, despite the fact that no anthropogenic radiative forcings are included in the simulations. The temperature trends during the past decades as observed and in the (ensemble mean) model response (Fig. 4) are roughly consistent with each other, which indicates that much of the land warming is a response to the warming of the oceans. The simulated land warming, however, is weaker than that observed in many regions, with an average land-sea warming ratio of 1.6, amounting to about $75 \%$ of the observed ratio of 2.1 . The mismatch reflects some part the missing effect of changes in radiative forcings in the ECHAM-HadISST simulation but will also reflect the transient imbalance in the observations, different local radiative forcings, internal chaotic fluctuations, model limitations, and uncertainties in the observations. Folland et al. (1998) found in a similar model study a smaller impact of the historical SST for the warming trends until 1994, but historical SST in their experiments alone could also reproduce a significant part of land surface warming. The above finding is in good agreement with the result of a recent study by Compo and Sardeshmukh (2009).

\section{Sensitivity experiments}

The above results may not be that surprising, considering that much earlier findings have already pointed out 


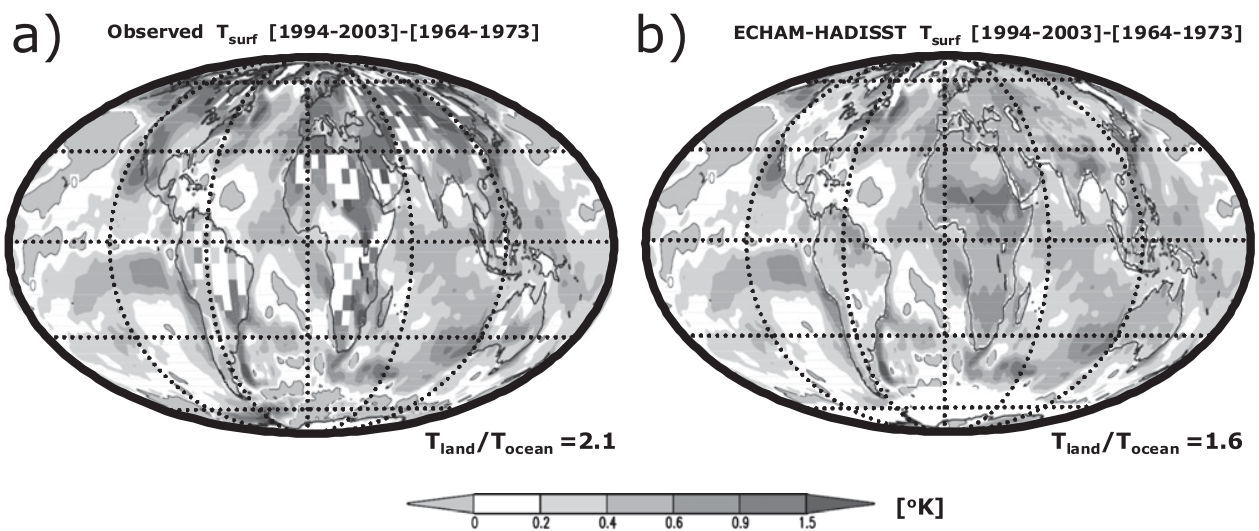

FIG. 4. (a) The mean observed $T_{\text {surf }}$ of the period 1994-2003 minus the period 1964-73. (b) As in (a), but for the simulations with historical SST forcing only (no other forcings; ensemble mean of ECHAMHadISST). Here $T_{\text {land }} / T_{\text {ocean }}$ is the ratio of the differences in $T_{\text {land }}\left(T_{\text {surf }}\right.$ over land $)$ and $T_{\text {ocean }}\left(T_{\text {surf }}\right.$ over ice-free oceans). Negative values have contour lines and undefined values in (a) are blank white squares.

that the land temperatures respond to increased ocean temperatures with enhanced amplitudes (e.g. Cess et al. 1990). However, these studies where focused on the climate sensitivity to external forcing and did not discuss these results in the context of ocean-land interactions in natural variability. So in the context of this study the simple response experiment of Cess et al. (1990) and Joshi et al. (2007) is repeated (see Fig. 5a). Most continental regions warm by more than $1 \mathrm{~K}(1.3-\mathrm{K}$ warming on average) if forced with uniform $1-\mathrm{K}$ warming of the global SST (Fig. 5a), indicating that positive feedbacks amplify the ocean forcing, which is in agreement with earlier findings.

If the experiment is repeated now with a uniform warming of the continents to estimate the ocean temperature response to $T_{\text {land }}$ in the coupled model, the SST increase is only $0.2 \mathrm{~K}$ (see Fig. 5b). None of the oceanic regions show an amplified response, but some regions show even a cooling as a response to warmed land (e.g., the eastern Pacific cold tongue region). Some of the structures in the SST response pattern resemble some known patterns related to atmospheric forcings, such as the Pacific decadal oscillation (PDO) pattern in the North Pacific. It needs to be noted, however, that the SST response in a fully dynamical ocean model will be significantly different in some regions from this simple $\mathrm{OZ}$ model, since no ocean dynamics are considered in the $\mathrm{OZ}$ simulations.

Finally, global change integrations are considered. Coupled and (partially) decoupled global warming integrations were compared. Figure $5 \mathrm{c}$ shows the quasiequilibrium response to a doubling of the atmospheric $\mathrm{CO}_{2}$ concentration in the coupled OZ-2 $\times \mathrm{CO}_{2}$ simulation. The typical land-sea contrast is clearly visible with a $73 \%$ stronger mean warming over land. The experiment is repeated with either the land or the ocean surface temperature fixed to climatology (Table 2). The important role of ocean-atmosphere interactions in both the land and ocean becomes obvious by comparing the warming response in the three experiments. Land warming is reduced by about $90 \%$ (from 5 to $0.6 \mathrm{~K}$ ) and ocean warming by about $70 \%$ ( 3 to $1 \mathrm{~K}$ ).

\section{A simple box model}

In the above analysis it was shown that the observed land-sea warming ratio is strongly dependent on the interaction between land and oceans. To quantify the relative importance of local feedbacks and the oceanland interaction, it is instructive to discuss a conceptual box model for the tendencies $T_{\text {land }}^{\prime}$ and $T_{\text {ocean }}^{\prime}$ (deviations from the climatological global mean surface temperature over land and over the ice-free oceans, respectively):

$$
\begin{gathered}
\lambda_{\text {land }} \frac{\partial T_{\text {land }}^{\prime}}{\partial t}=c_{L} T_{\text {land }}^{\prime}+c_{\mathrm{LO}}\left(T_{\text {ocean }}^{\prime}-T_{\text {land }}^{\prime}\right)+F_{L}, \\
\lambda_{\text {ocean }} \frac{\partial T_{\text {ocean }}^{\prime}}{\partial t}=c_{O} T_{\text {ocean }}^{\prime}+c_{\mathrm{OL}}\left(T_{\text {land }}^{\prime}-T_{\text {ocean }}^{\prime}\right)+F_{O} .
\end{gathered}
$$

The feedback parameters $c_{L}$ and $c_{O}$ represent the net effects of all local feedbacks. The coupling between the land and ocean regions are simplified by a Newtonian approach, with the effective coupling parameters $c_{\mathrm{LO}}$ and $c_{\mathrm{OL}}$. Thus $c_{\mathrm{LO}}$ and $c_{\mathrm{OL}}$ summarize all processes that lead to a linear interaction between ocean and land, 
a)

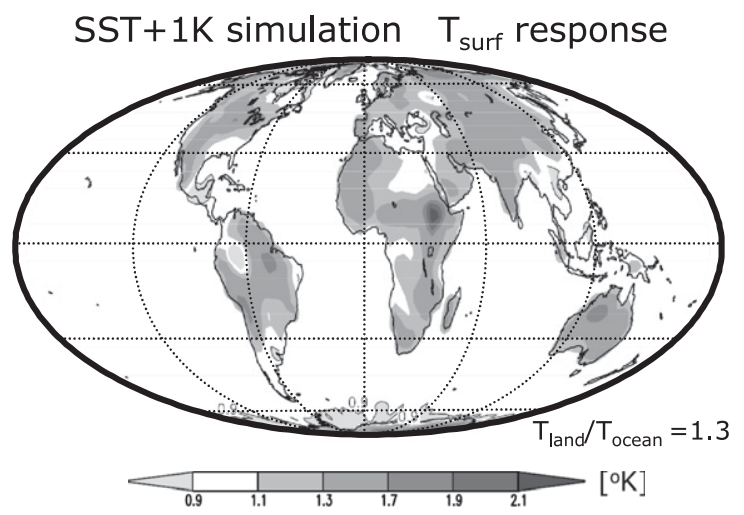

b)

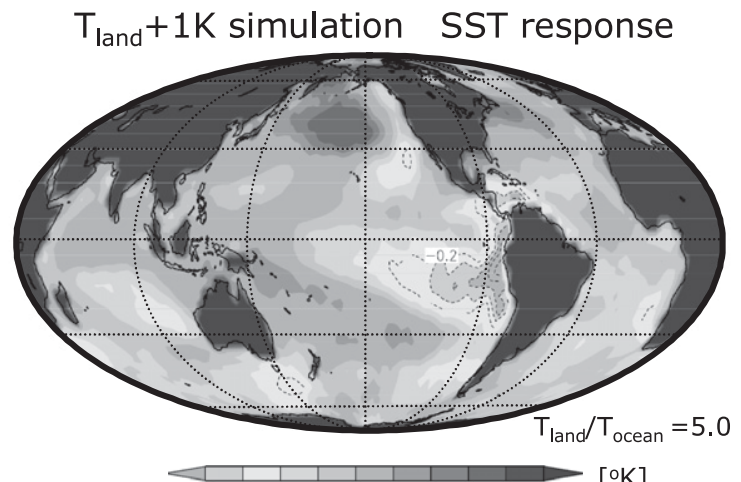

c)

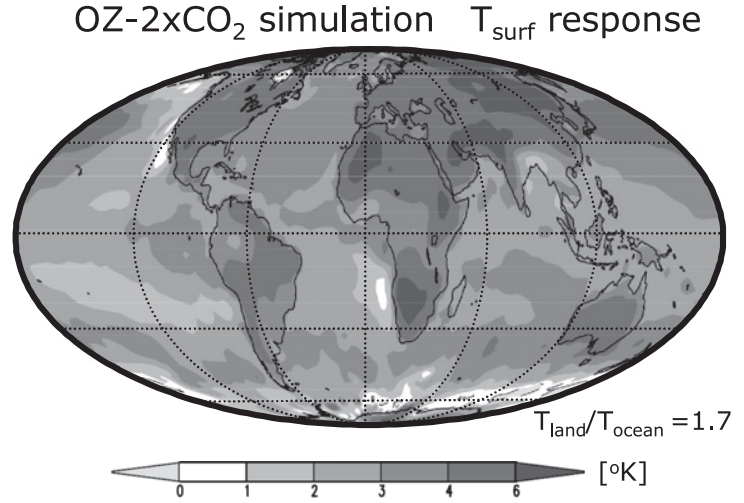

FIG. 5. (a) Mean response in $T_{\text {surf }}$ to 1-K uniform SST increase (SST + 1K). (b) Mean response in SST to 1-K uniform increase of $T_{\text {surf }}$ over land (TLAND $+1 \mathrm{~K}$ ). (c) The mean $T_{\text {surf }}$ response over the last $20 \mathrm{yr}$ of a 2 times $\mathrm{CO}_{2}$ concentration simulation $(\mathrm{OZ}-2 \times$ $\left.\mathrm{CO}_{2}\right)$. Here $T_{\text {land }} / T_{\text {ocean }}$ is the ratio of the differences in $T_{\text {land }}\left(T_{\text {surf }}\right.$ over land) and $T_{\text {ocean }}\left(T_{\text {surf }}\right.$ over ice-free oceans). Contours in (a) mark values $<1.0$ and in (b),(c) mark negative values.

which in the real world would be realized by the turbulent exchange of heat, energy, or moisture via the atmospheric circulation. External forcing such as changes in $\mathrm{CO}_{2}$ concentration is simplified to a net forcing over land $F_{L}$ and over the ocean $F_{O}$; see Fig. 6 for an illustrating sketch. The different heat capacities over land and ocean are given by $\lambda_{\text {land }}$ and $\lambda_{\text {ocean }}$, respectively. In equilibrium, the system reduces to
TABLE 2. Mean response of $T_{\text {surf }}$ over land ( $\left.T_{\text {land }}^{\prime}\right)$ and oceans $\left(T_{\text {ocean }}^{\prime}\right)$ in different experiments. Prescribed values are in brackets.

\begin{tabular}{lccc}
\hline \multicolumn{1}{c}{ Experiment } & $T_{\text {land }}^{\prime}$ & $T_{\text {ocean }}^{\prime}$ & $T_{\text {land }}^{\prime} / T_{\text {ocean }}^{\prime}$ \\
\hline $\mathrm{SST}+1 \mathrm{~K}$ & 1.3 & {$[1.0]$} & 1.3 \\
$\mathrm{TLAND}+1 \mathrm{~K}$ & {$[1.0]$} & 0.2 & 5.0 \\
$\mathrm{OZ}-2 \times \mathrm{CO}_{2}$ & $5.0^{*}$ & $3.0^{*}$ & 1.7 \\
FIXSST-2 $\times \mathrm{CO}_{2}$ & $0.6^{*}$ & {$[0.0]$} & - \\
FIXLAND-2 $\times \mathrm{CO}_{2}$ & {$[0.0]$} & $1.0^{*}$ & - \\
\hline
\end{tabular}

* Mean response over the last $20 \mathrm{yr}$ of the simulation.

$$
\begin{gathered}
{\left[c_{L}-\left(1-\frac{c_{\mathrm{OL}}}{c_{\mathrm{OL}}-c_{O}}\right) c_{\mathrm{LO}}\right] T_{\text {land }}^{\prime}} \\
+\frac{c_{\mathrm{LO}}}{c_{\mathrm{OL}}-c_{O}} F_{O}+F_{L}=0 .
\end{gathered}
$$

Here $F_{L}$ and $F_{O}$ can be regionally different because of differences in $T_{\text {surf }}$, water vapor, clouds, and aerosol. The FIXSURF-2 $\times \mathrm{CO}_{2}$ experiment allows a rough estimate of $F_{L}=2.4 \mathrm{~W} \mathrm{~m}^{-2}$ and $F_{O}=1.3 \mathrm{~W} \mathrm{~m}^{-2}$ since the main feedbacks due to a $T_{\text {surf }}$ response are not active. The smaller effective forcing over ocean may be related to the larger water vapor content. Note that the different sensitivities favor a land-sea contrast but are not the main cause for it, as will be discussed below and is also pointed out by (Joshi et al. 2007).

Based on the global mean response in $T_{\text {land }}^{\prime}$ and $T_{\text {ocean }}^{\prime}$ in the experiments (Table 2), one can estimate the four unknown parameters $\left(c_{L}, c_{O}, c_{\mathrm{LO}}\right.$, and $\left.c_{\mathrm{OL}}\right)$; see Fig. 6 . The uncertainties in the parameters are difficult to estimate because of the small number of values used to estimate them. However, it can first be recognized that this simple box model describes the global mean response in $T_{\text {land }}^{\prime}$ and $T_{\text {ocean }}^{\prime}$ in all simulations in Table 2 relatively well with a root-mean-square error of $0.09 \mathrm{~K}$. Some crude estimate of the uncertainty in the parameters can be gained if only a subset of the global mean response values in Table 2 is used (although some information is lost) to estimate the model parameters. The ranges of values resulting from these estimates are $c_{L}=(0.7,1.9) \mathrm{W} \mathrm{K}^{-1} \mathrm{~m}^{-2}$, $c_{O}=(-0.5,-1.0) \mathrm{W} \mathrm{K}^{-1} \mathrm{~m}^{-2}, c_{\mathrm{LO}}=(2.8,5.9) \mathrm{W} \mathrm{K}^{-1} \mathrm{~m}^{-2}$, $c_{\mathrm{OL}}=(0.1,0.5) \mathrm{W} \mathrm{K}^{-1} \mathrm{~m}^{-2}$, and $c_{\mathrm{LO}} / c_{\mathrm{OL}}=(6,45)$. This model is obviously a strong simplification, which neglects many regional differences, but for global-scale variability this model seems to be a decent approximation. It needs also to be noted that the parameters of this model are derived from coupled and uncoupled simulations. It is hence assumed that both types of experiments represent basically the same system. The uncoupled simulations (e.g., SST $+1 \mathrm{~K}$ or TLAND $+1 \mathrm{~K}$ ) may, however, produce spurious results at least for the mid- and higher latitudes (see, e.g., Barsugli and Battisti 1998; Dommenget 2000; Sutton and Mathieu 2002). 


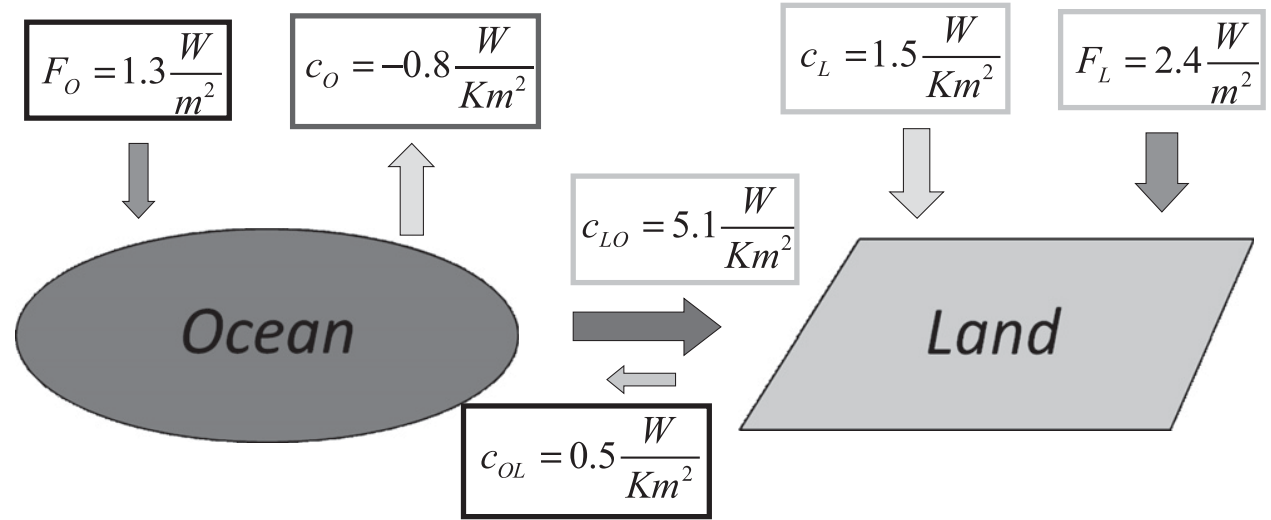

FIG. 6. The sketch illustrates the simple box model and shows the parameter values as estimate from a least squares fit to the global mean response values in Table 2.

However, the previous analysis has shown that uncoupled and coupled simulations have similar characteristics in the land-sea warming ratio in the tropics. Furthermore, the good agreement of this simple model with both the coupled and uncoupled simulations may also give some indication that the uncoupled simulations are, in the context of this work, not too different from the coupled simulations. For the mid- and higher latitudes some caution in the interpretation of these results should, however, be noted.

The results of this simple box model can be summarized by the following main findings:

- The continental climate responds to the ocean forcing with a local positive feedback of $c_{L}=1.5 \mathrm{~W} \mathrm{~K}^{-1} \mathrm{~m}^{-2}$, consistent with earlier studies (e.g. Cess et al. 1990). In turn, the ocean responds to the continental forcing with a local negative feedback of $c_{O}=-0.8 \mathrm{~W} \mathrm{~K}^{-1} \mathrm{~m}^{-2}$. The differences in these feedbacks are likely to be related to the different latent heat release and water vapor content (Sutton et al. 2007; Joshi et al. 2007).

- The land surface temperature is roughly 10 times more sensitive to the ocean temperature changes $\left(c_{\mathrm{LO}}=\right.$ $5.1 \mathrm{~W} \mathrm{~K}^{-1} \mathrm{~m}^{-2}$ ) than the ocean temperature is to changes over land $\left(c_{\mathrm{OL}}=0.5 \mathrm{~W} \mathrm{~K}^{-1} \mathrm{~m}^{-2}\right)$.

- Following Eq. (3), the continental climate is more strongly forced by $F_{O}$ than by $F_{L}$. It also follows that the land-sea warming ratio is caused by the different coupling and feedback parameters over land and ocean and not by the differences in $F_{L}$ and $F_{O}$. The latter is in agreement with the findings of Joshi et al. (2007).

- The anthropogenic change in $T_{\text {land }}$ [Eq. (1)] is $86 \%$ a response to the ocean temperature change and only $14 \%$ a response to local forcing. The anthropogenic radiative forcing heats up the oceans, which then by land-sea interaction warms the land. The ocean tem- peratures are, therefore, not lagging behind the fast warming of the continents but are indeed the driving force for the continental warming. Prescribing historical SST changes will reproduce a large fraction of the continental climate change in atmosphere-only GCM integrations. This is in agreement with the findings of Compo and Sardeshmukh (2009). It may also explain why Zhang et al. (2007) were able to reproduce the decadal $T_{\text {land }}$ variability of the Northern Hemisphere by prescribing the historical SST variability in the North Atlantic. Subsequently monitoring the ocean state is more important for continental temperature change predictions than to observe land surface temperatures itself.

- The simple model may also be used to explore the results of the ECHAM-HadISST simulation or the coupled model OZ. To study the internal transient climate variability we may assume that $F_{O}$ and $F_{L}$ represent internal weather noise forcing, which may be of similar amplitudes over land and oceans [amplitude $\left.\left(F_{O}\right)=\operatorname{amplitude}\left(F_{L}\right)\right]$, but with fluctuations over land and oceans that are independent of each other. This is basically justified by the similar strength of weather fluctuations (24-h mean) in the free atmosphere $(500 \mathrm{hPa})$ over land and oceans. We further need to consider the limited heat capacity of land and ocean, which we assume to be the equivalent of a $2-\mathrm{m}$ water column for the land and 100-m water column for the oceans. Integrating the model with these parameters we find that the land-sea ratio (as defined in Fig. 2) is $T_{\text {land }} / T_{\text {ocean }}=1.5$ and the correlation is $r=$ 0.8 , which is in good agreement with the results of the ECHAM-HadISST experiment.

- The above results of the simple box model may wrongly be interpreted as an indication that the $T_{\text {land }}$ should be lagging behind the time evolution of $T_{\text {ocean }}$, since the latter is the most important forcing for the 
III.) Latent heat release
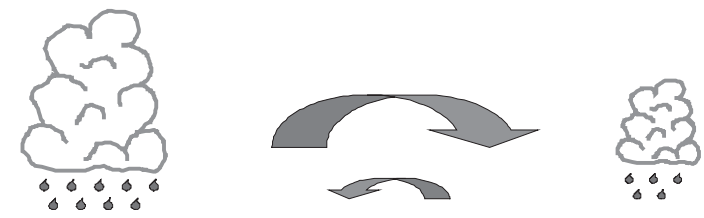

II.) Water vapour release

\{\}

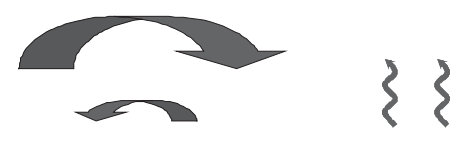

\section{I.) Temperature (heat)}
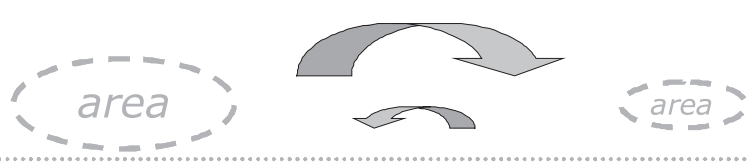

ocean

\section{land}

FIG. 7. The sketch illustrates the asymmetry in ocean-land interaction due to three characteristics. The oceans force the land more strongly because of the larger ocean area (I), larger atmospheric water vapor supply (II), and because of latent heat release in the upper troposphere (III). Larger arrows indicate stronger forcing in the direction of the arrow for a given surface temperature change.

$T_{\text {land. }}$ But, because of the different heat capacities of land and ocean and the consequent larger variability over land, the model predicts that the $T_{\text {land }}$ should lead the time evolution of the $T_{\text {ocean }}$ by about a month, depending on the values of $\lambda_{\text {land }}, \lambda_{\text {ocean }}, F_{O}$, and $F_{L}$.

\section{Asymmetry in land-ocean interaction}

The observations, GCM model simulations, and the simple conceptual box model all suggest that the interaction between land and oceans is strongly asymmetric, with an about 10 times larger influence of the ocean to the land than vice versa. Three different characteristics of the earth climate may lead to this asymmetry in the interaction (see sketch in Fig. 7):

1) The area covered with oceans is twice as large as the land area and, because of the unequal distribution of land and oceans on earth, a land point is on average much closer to the ocean than an ocean point is to land. While this could explain some asymmetry in the land-sea interaction, it could not explain the amplified response of $T_{\text {land }}$ to changes in $T_{\text {ocean }}$.

2) A 1-K warming of the oceans leads, on average, to a larger increase in atmospheric water vapor content than a $1-\mathrm{K}$ warming over land because of the obvious larger availability of moisture over oceans. Thus the advection of warmer air from the ocean onto land goes along with additional advection of increased water vapor content, which leads to an increase of incoming longwave radiation. This positive radiative feedback can increase the effective coupling of the land to the ocean's temperature and may contribute to the amplification of the response in $T_{\text {land }}$ to changes in $T_{\text {ocean }}$.

3) Related to the increased water vapor over oceans, latent heat is released to the atmosphere, reducing lapse rates and heating the upper-tropospheric levels (Joshi et al. 2007). Thus the troposphere is warmed at the surface by increased SST and additionally warmed by latent heat release at higher levels, which will by atmospheric circulation influence the land. This may increase the effective coupling of the land to the ocean's temperature and could also contribute to the amplification of the response in $T_{\text {land }}$ to changes in $T_{\text {ocean }}$.

A direct verification of these effects is beyond the scope of this study, but some simple considerations and statistics of the model simulations may illustrate that these processes may indeed contribute to the asymmetry in land-sea interaction.

The effect that the unequal distribution of land and ocean area would have on the ratio of $c_{\mathrm{LO}} / c_{\mathrm{OL}}$ can be estimated by a simple isotropic diffusion model with a globally constant diffusion parameter $\kappa$ and local 
a)

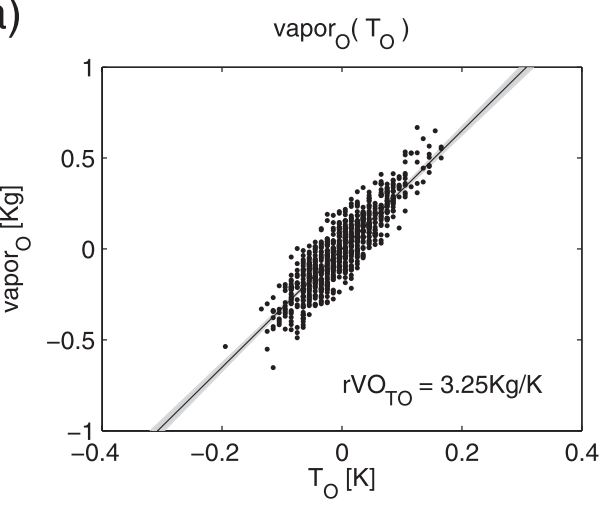

c)

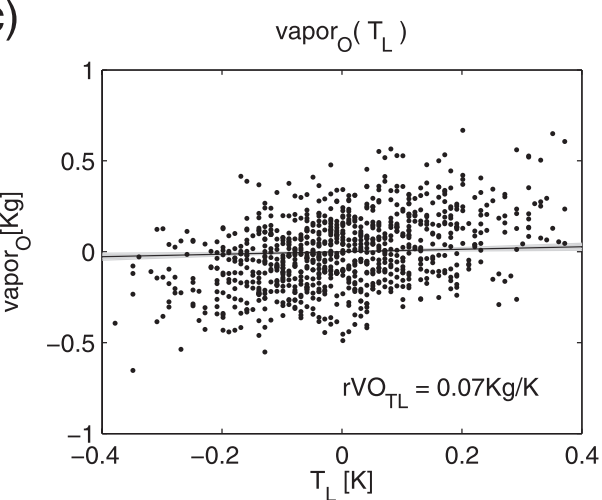

b)

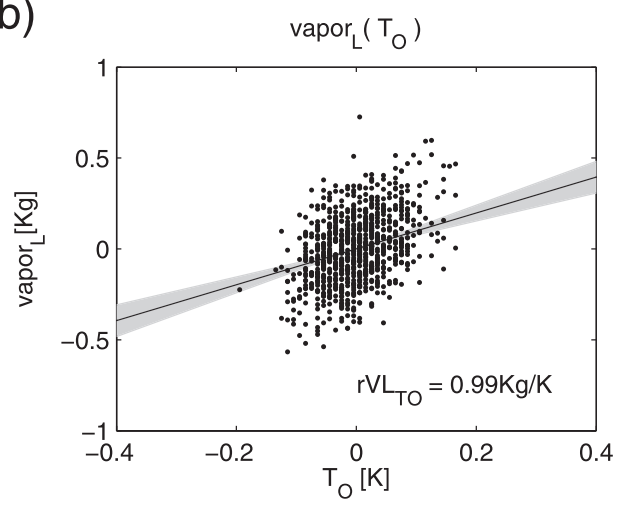

d)

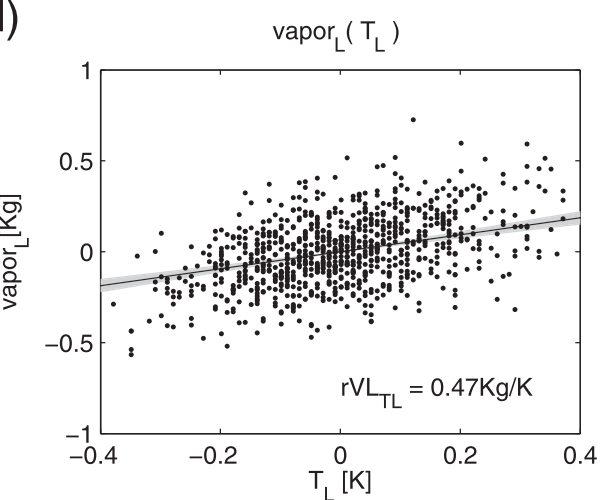

FIG. 8. Scatterplots of the integrated atmospheric water vapor over (left) oceans and (right) land as function of (top) $T_{\text {ocean }}$ and (bottom) $T_{\text {land }}$ in the $\mathrm{OZ}$ simulation. The regression values and lines of the bivariate linear regression coefficients for integrated atmospheric water vapor as a linear function $T_{\text {ocean }}$ and $T_{\text {land }}$ are shown as well. Note that, because of the bivariate model, the regression lines do not need to fit to the main axis of the scattered point distribution, since $T_{\text {ocean }}$ and $T_{\text {land }}$ are not orthogonal to each other. The shaded areas around the regression lines mark the $90 \%$ confidence intervals linear regression coefficients.

damping parameters $c_{L}$ and $c_{O}$ as in the box model. In this simple isotropic diffusion model the strength of the diffusivity $\kappa$ and the local damping parameters $c_{L}$ and $c_{O}$ control the values of the diagnostic parameters $c_{\mathrm{LO}}$ and $c_{\mathrm{OL}}$, which can be estimated from the resulting temperature response as done for the GCM simulations. If we adjust $\kappa$ to reproduce the $T_{\text {land }}$ response in the SST $+1 \mathrm{~K}$ experiment and the $T_{\text {ocean }}$ response in TLAND $+1 \mathrm{~K}$, we find that this is not possible with a constant $\kappa$, suggesting some asymmetry in the land-sea interaction beyond the given land-sea distribution. If we adjust the value $\kappa$ to each experiment individually, we find in both cases that the isotropic diffusion model would suggest a ratio of $c_{\mathrm{LO}} / c_{\mathrm{OL}} \approx 3$ caused by the asymmetry in the land-sea distribution. Thus, the GCM experiments find a much stronger sensitivity of $T_{\text {land }}$ toward changes in $T_{\text {ocean }}$ than expected from a simple diffusion model. The real world is, of cause, much more complex than an isotropic diffusion model, with large anisotropies and different mean advection directions in different regions. However, there is no obvious reason why those should lead to a 10 times stronger sensitivity of the land to ocean temperature change. The results therefore suggest that some additional processes cause the asymmetry in the land-ocean interactions.

The second effect of increased atmospheric water vapor due to warming in $T_{\text {ocean }}$ or $T_{\text {land }}$ may be illustrated by a simple bivariate linear regression model fitted to the variability of the coupled simulation OZ (see Fig. 8). Naturally the atmospheric water vapor content is increasing if the local surface temperatures are increasing (Figs. 8a,d), and naturally this effect is stronger over the oceans (Fig. 8a). But more interestingly in the context of this study is that the atmospheric water vapor content over land is more sensitive to the remote $T_{\text {ocean }}$ than it is to $T_{\text {land }}$ (cf. Fig. 8b with Fig. 8d), and the atmospheric water vapor content over the oceans is essentially independent of $T_{\text {land }}$ (Fig. 8c). This supports the idea that warmer $T_{\text {ocean }}$ increases atmospheric water vapor content, which is advected by the atmospheric 

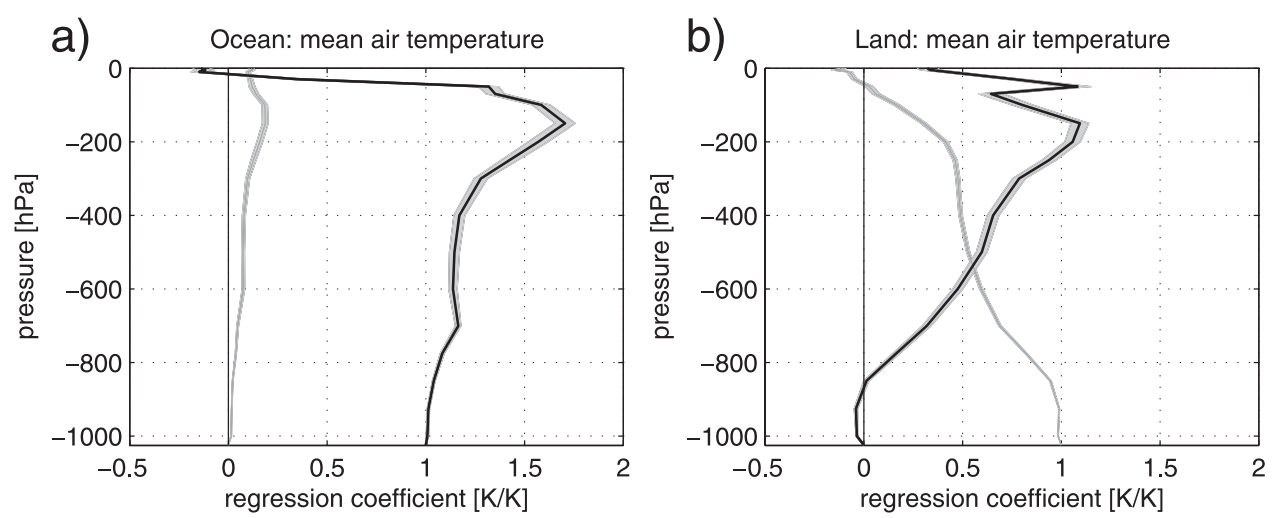

FIG. 9. Bivariate linear regression coefficients for the air temperature over (left) ice-free oceans and (right) the land as linear model of $T_{\text {land }}$ (light gray lines) and $T_{\text {ocean }}$ (black lines) fit to the OZ simulation data. Shaded areas indicate the regression coefficients $90 \%$ confidence interval. Note that $T_{\text {land }}$ and $T_{\text {ocean }}$ are not orthogonal to each other and therefore a zero regression coefficient of one of the two variables for the air temperature cannot be interpreted as a zero influence on the latter.

circulation toward continental regions, while in return $T_{\text {land }}$ has no such effect. The increased atmospheric water vapor content over land leads on average to $1.3 \mathrm{~W} \mathrm{~m}^{-2}$ longwave surface heating per $\mathrm{Kg} \mathrm{m}^{-2}$ atmospheric water vapor content increase in interannual variability of the ECHAM-OZ simulation, which is comparable to the estimates of the local radiative forcings $\left(F_{O}\right.$ and $\left.F_{L}\right)$ in the FIXSURF- $2 \times \mathrm{CO}_{2}$ experiment (see section 5). It is therefore likely to be a significant positive feedback to changes in $T_{\text {ocean }}$ on interannual and longer time scales.

Joshi et al. (2007) basically argue that the ratio in land-ocean warming trends is maintained by a stronger effect of $T_{\text {ocean }}$ on the higher (above the boundary layer) tropospheric air temperature than $T_{\text {land }}$ and by the global mixing of the higher tropospheric air temperatures that leads to a coupling between $T_{\text {ocean }}$ and $T_{\text {land }}$. The different effects that $T_{\text {ocean }}$ and $T_{\text {land }}$ have on the free atmosphere temperatures in interannual climate variability in the coupled simulation $\mathrm{OZ}$ can be estimated by means of a simple bivariate linear regression model (see Fig. 9). The influence of $T_{\text {land }}$ on the air temperature over land is roughly linear decreasing with height, while the influence of $T_{\text {ocean }}$ on the air temperature over oceans increases with height until about $200 \mathrm{hPa}$. It supports the idea 3 (in sketch Fig. 7) that $T_{\text {ocean }}$ influences the free troposphere more strongly than $T_{\text {land }}$. Furthermore, we find that the influence of $T_{\text {ocean }}$ on the air temperature over land is much stronger than the influence of $T_{\text {land }}$ on the air temperature over oceans. This again supports the idea that the arguments of Joshi et al. (2007) hold also for interannual variability in $T_{\text {ocean }}$ and $T_{\text {land }}$.

The results presented above are qualitatively the same for the ECHAM-HadISST simulations, supporting the idea that the uncoupled simulations basically represent a similar climate system.

\section{Summary and discussion}

In this study the land-sea contrast, reflecting stronger warming over land than over oceans, was reinvestigated in observations and in a series of GCM simulations. Previous studies on this issue focused either on the climate sensitivity to anthropogenic forcings (e.g., Cess et al. 1990) or on highlighting that this land-sea contrast exists in global warming scenario simulations beyond simple transient effects (Sutton et al. 2007; Lambert and Chiang 2007; Joshi et al. 2007). In particular Joshi et al. (2007) illustrated that this land-sea contrast in global warming scenarios is maintained by latent heat release in the free atmosphere and the associate atmospheric lapse rates. It therefore represents a mechanism that appears to be intrinsic to the climate system. A somewhat overlooked subject in the discussion of these previous studies is the implication that these findings have on the ocean-land interaction in natural climate variability, which was the focus of this study.

It was shown in observations, as well as in GCM simulations, that the land-sea contrast exists in interannual $T_{\text {surf }}$ variability, which was also indicated by Lambert and Chiang (2007). Model simulations further showed that interannual variability of global $T_{\text {ocean }}$ leads to a coherent response of $T_{\text {land }}$ with amplified amplitudes, causing a significant part of the longer (interannual to decadal) time-scale $T_{\text {land }}$ variability.

A simple box model, which summarized the GCM simulation results, suggested that $T_{\text {land }}$ is about 10 times more sensitive to $T_{\text {ocean }}$ than $T_{\text {ocean }}$ is to $T_{\text {land }}$. A simple isotropic diffusion model with realistic land-sea 
distribution suggested that this asymmetry in the landocean interaction is not just due to the asymmetric ocean-land area distribution but must be supported by some additional asymmetric feedbacks. Regression analysis of the vertical temperature variability related to $T_{\text {ocean }}$ and $T_{\text {land }}$ variability support the idea that the latent heat release in the upper troposphere over oceans, as discussed in Joshi et al. (2007), may contribute to the asymmetry in the land-ocean interaction. The relation of the integrated atmospheric water vapor variability to $T_{\text {ocean }}$ and $T_{\text {land }}$ variability further support the idea that the advection of atmospheric water vapor, which is released into the atmosphere coherently with warming of $T_{\text {ocean }}$, may contribute to the asymmetry in the landocean interaction.

The results suggest that natural ocean temperature variability will lead to variability with amplified magnitudes in $T_{\text {surf }}$ over continents. However, the study here only considers global mean values, but the effect that natural ocean variability will have on continental temperatures will strongly dependent on the size, pattern, and region of the ocean temperature variability. Many natural modes of SST variability (e.g., El Niño) are far away from the main continents and often the patterns are multipoles, with positive and negative temperature variability at different region at the same time, which may cancel each other out once they reach the land. Furthermore, the amplification may be related to evaporation over oceans, which is clearly a function of the mean temperature of the oceans and will therefore have clear regional differences. Detecting the amplified magnitudes in $T_{\text {surf }}$ over continents for such natural patterns of variability may, therefore, be difficult. However, the teleconnections of El Niño over northern North America, which is more than $4000 \mathrm{~km}$ away from the origin of El Niño, can, for instance, lead to amplitudes in winter surface temperature larger than the original El Niño signal (Ropelewski and Halpert 1986). Basinwide warming and cooling will most likely have the strongest impact on surface temperatures of adjacent continents.

The results of internal coupled model variability of the OZ simulation were somewhat different from the observations or the simulation forced with observed SST variability (ECHAM-HadISST), indicating that the results related to the internal variability may to some degree be model dependent. To some extent this may be due to the missing tropical coupled dynamics in the OZ simulation and due to somewhat different variability in the higher northern latitudes. It will, in general, depend on the mean state of the coupled simulation and the structure of the internal modes of variability. In these characteristics coupled GCM models differ a lot from observations and from each other. It is therefore possi- ble or even likely that the results will differ in different GCM simulations or, more generally, will depend on the climate mean state itself. Further analysis is needed to understand the model dependencies and the regional differences in land-ocean interactions.

Acknowledgments. Thanks to Noel Keenlyside, Mojib Latif, and Vladimir Semenov for discussions and Noel Keenlyside for providing the ECHAM-HadISST simulations. I would also like to thank the anonymous referees for their comments, which helped to improve the analysis significantly. The ECHAM-HadISST simulations were run at the German supercomputing center HLRN.

\section{REFERENCES}

Barsugli, J. J., and D. S. Battisti, 1998: The basic effects of atmosphere-ocean thermal coupling on midlatitude variability. J. Atmos. Sci., 55, 477-493.

Brohan, P., J. J. Kennedy, I. Harris, S. F. B. Tett, and P. D. Jones, 2006: Uncertainty estimates in regional and global observed temperature changes: A new dataset from 1850. J. Geophys. Res., 111, D12106, doi:10.1029/2005JD006548.

Cess, R. D., and Coauthors, 1990: Intercomparison and interpretation of climate feedback processes in 19 atmospheric general circulation models. J. Geophys. Res., 95 (D10), 16 601-16 615.

Compo, G. P., and P. D. Sardeshmukh, 2009: Oceanic influences on recent continental warming. Climate Dyn., 32, 333-342, doi:10.1007/s00382-008-0448-9.

Dommenget, D., 2000: Large-scale SST variability in the midlatitudes and in the tropical Atlantic. Ph.D. thesis, MPI Examensabeit 76, Geosciences, University of Hamburg, 120 pp.

— Geophys. Res. Lett., 35, L02706, doi:10.1029/2007GL031087.

Folland, C. K., D. M. H. Sexton, D. J. Karoly, C. E. Johnson, D. P. Rowell, and D. E. Parker, 1998: Influences of anthropogenic and oceanic forcing on recent climate change. Geophys. Res. Lett., 25, 353-356.

Joshi, M. M., J. M. Gregory, M. J. Webb, D. M. H. Sexton, and T. C. Johns, 2007: Mechanisms for the land/sea warming contrast exhibited by simulations of climate change. Climate Dyn., 30, 455-465, doi:10.1007/s00382-007-0306-1.

Lambert, F. H., and J. C. H. Chiang, 2007: Control of land-ocean temperature contrast by ocean heat uptake. Geophys. Res. Lett., 34, L13704, doi:10.1029/2007GL029755.

Latif, M., N. S. Keenlyside, and J. Bader, 2007: Tropical sea surface temperature, vertical wind shear, and hurricane development. Geophys. Res. Lett., 34, L01710, doi:10.1029/2006GL027969.

Pielke, R. A., Sr., and Coauthors, 2007: Unresolved issues with the assessment of multidecadal global land surface temperature trends. J. Geophys. Res., 112, D24S08, doi:10.1029/ 2006JD008229.

Rayner, N. A., D. E. Parker, E. B. Horton, C. K. Folland, L. V. Alexander, D. Rowell, E. C. Kent, and A. Kaplan, 2003: Global analyses of sea surface temperature, sea ice, and night marine air temperature since the late nineteenth century. J. Geophys. Res., 108, 4407, doi:10.1029/2002JD002670.

Roeckner, E., and Coauthors, 2003: The atmospheric general circulation model ECHAM5. Part I: Model description. Max 
Planck Institute for Meteorology, Hamburg, Germany, MPI Rep. 349, 127 pp.

Ropelewski, C. F., and M. S. Halpert, 1986: North America precipitation and temperature patterns associated with the El Niño/ Southern Oscillation (ENSO). Mon. Wea. Rev., 114, 2352-2362.

Sutton, R., and P.-P. Mathieu, 2002: Response of the atmosphereocean mixed-layer system to anomalous ocean heat-flux convergence. Quart. J. Roy. Meteor. Soc., 128, 1259-1275.
_ B. Dong, and J. M. Gregory, 2007: Land/sea warming ratio in response to climate change: IPCC AR4 model results and comparison with observations. Geophys. Res. Lett., 34, L02701, doi:10.1029/2006GL028164.

Zhang, R., T. L. Delworth, and I. M. Held, 2007: Can the Atlantic Ocean drive the observed multidecadal variability in Northern Hemisphere mean temperature? Geophys. Res. Lett., 34, L02709, doi:10.1029/2006GL028683. 